\title{
FUNÇÃO E IMPORTÂNCIA DA MIELINA NO SISTEMA NERVOSO CENTRAL: MIELINIZAÇÃO E DESMIELINIZAÇÃO
}

Francis Moreira da Silveira ${ }^{1}$

Prof. Dr. MD. Bensson V. Samuel, Ph.D2

RESUMO: Formada por camadas bimoleculares de lípides intercaladas com proteínas, a mielina constitui um importante elemento do Sistema Nervoso Central e Periférico, atuando como uma bainha que envolve os tratos nervosos, facilitando a rápida comunicação entre os neurônios. São sintetizados e mantidos pelos oligodendrócitos, uma das células mais vulneráveis do sistema nervoso, que formam um número variável de segmentos de mielina, chamados internódulos, que variam entre 1 e 200. Desse modo, quando ocorre lesão em uma célula, podem ser destruídos inúmeros internódulos, em um processo denominado desmielinizante, provocando uma série de complicações. Com isso, este trabalho tem como objetivo analisar a função da mielina no sistema nervoso e as complicações clinicas de sua degeneração.

PALAVRAS-CHAVE: Mielina. Sistema Nervoso Central. Degeneração.

\section{INTRODUÇÃO}

O Sistema Nervoso Central (SNC) é constituído pelas substâncias branca e cinzenta. Enquanto a substância cinzenta microscopicamente corresponde à região de maior densidade de elementos neuronais, a substância branca possui

\footnotetext{
${ }^{1}$ Médico Psiquiatra - Membro efetivo da associação Brasileira de Neuropsiquiatria

E-mail: drfrancismsilveira@gmail.com

${ }^{2}$ Chanceler da UniLogos, Médico (USA), Professor e Orientador titular dos programas de Saúde, Ph.D.
} 
alguns tipos neuronais e uma grande quantidade de axônios mielinizados, que provocam essa aparência esbranquiçada.

A bainha de mielina, enquanto uma estrutura lipoprotéica, posicionada envolta de axônios e disposta em internódulos, permite a condução saltatória de maneira rápida, ágil e eficaz na transmissão dos impulsos nervosos, sendo construída a partir de oligodendrócitos, no Sistema Nervoso Central (SNC), e a célula de Schwann, no Sistema Nervoso Periférico (SNP).

Um oligodendrócito, mais frequente na substância branca, mieliniza um ou inúmeros axônios, ao passo em que a célula de Schwann constitui apenas um internódulo de mielina, demonstrando a gravidade de uma lesão no oligodendrócito, superior a destruição de uma célula de Schwann, provocando uma série de consequências patológicas e clínicas.

Os oligodendrócitos se apresentam nessa dinâmica como células mielinizantes do Sistema Nervoso Central, que são responsáveis pela produção e manutenção dos internodos das bainhas de mielina, o que permite a condução saltatória, justificando a rápida comunicação entre o SNC e o restante do corpo humano. Além disso essas células são capazes de envolver os Nodos de Ranvier e as Sinapses juntamente com atrócitos, ajudando a se manter a homeostase, até mesmo da atividade elétrica neuronal. (Blaschuk; Constant, 1998).

Possui composição idêntica às membranas celulares, traduzindo em números composta por $70 \%$ de lípides e $30 \%$ de proteínas, a bainha de mielina apresenta em sua composição elevada concentração de colesterol e fosfolípedes, que, como ressaltado anteriormente, no Sistema Nervoso Central, é produzida pelas células oligodendrócitos, e iniciada a partir de estímulos dos astrócitos, enquanto no Sistema Nervoso Periférico produzida pelas células Shwann, é iniciada a partir da presença do axônio. Essa é a estrutura básica de formação da mielina, que no SNC tem, em pelo menos sua metade, como proteína principal o Proteolípideo, que devido à presença insolúvel em água de aminoácidos hidrofóbicos, é insolúvel em água.

Nessa estrutura, a célula de Scwann produz mielina para apenas um axônio, tornando a bainha um seguimento, mais precisamente um alongamento, 
de seu próprio citoplasma. Por outro lado, a célula oligodendrócito é capaz de produzir para diversos axônios.

Com isso, este presente artigo tem como objetivo analisar a Mielina, seu processo de formação, sua composição, e sua função no Sistema Nervoso. Para tanto é necessário, primeiramente, discorrer sobre o Tecido Nervoso, e seus principais componentes, podendo assim analisar a estrutura que envolve a bainha de mielina, e todos os elementos que participam dessa dinâmica.

Posteriormente será estudada a mielina em si, buscando compreender, a partir de seu papel no Sistema Nervoso, quais as consequências de possíveis lesões que atingem essa área do organismo.

\section{COMPOSIÇÃO DO TECIDO NERVOSO}

O Sistema Nervoso tem como papel a recepção e transmissão de impulsos elétricos, sendo dividido anatomicamente em Sistema Nervoso Central (SNC) e Sistema Nervoso Periférico (SNP). Assume a função de comunicação do organismo com o meio externo, transmissão de sinal efetor para músculos e glândulas, coordenar as funções orgânicas, e também atuam na percepção, memória, aprendizado e linguagem. (Montanari, 2016).

O tecido nervoso recebe informações do meio ambiente através dos sentidos (visão, audição, olfato, gosto e tato) e do meio interno, como temperatura, estiramento e níveis de substâncias. Processa essas informações e elabora uma resposta que pode resultar em ações, como a contração muscular e a secreção de glândulas, em sensações, como dor e prazer, ou em informações cognitivas, como o pensamento, o aprendizado e a criatividade. Ele é ainda capaz de armazenar essas informações para uso posterior: é a memória. (MONTANARI, 2016, p. 84).

O SNC é formado pelo encéfalo, elementos neurais do sistema fotorreceptor e da medula espinhal, enquanto o SNP é constituído por nervos, terminações nervosas e gânglios. (Junqueira; Carneiro, 2008). No sistema nervoso central se apresenta a substância cinzenta, com astrócito fibroso, e a substância branca, com astrócito protoplasmático, onde a primeira dispõe de 
corpos celulares de neurônios, dendritos, células da Glia e uma porção inicial do axônio não mielinizado.

Sendo o principal responsável pela rápida troca de informações rápidas nos animais, o Tecido Nervoso é composto, no sistema nervoso central, primordialmente por neurônios, células que apresentam frequentemente longos prolongamentos e diversos tipos de células da Glia ou neuroGlia, como os astrócitos, oligodendrócitos e micróGlia. No sistema nervoso periférico apresenta neurônio, célula de Scwann e células satélites. (Junqueira; Carneiro, 2008).

Os tipos celulares que compõem o sistema nervoso são os neurônios e a neuróglia ou glia (AIZENMAN et al., 1989; GRITTI; BONFANTI, 2007). No SNC, a neuróglia é composta por células ependimárias, pela micróglia e pela macróglia, esta compreendendo os astrócitos (protoplasmáticos e fibrosos) e os oligodendrócitos (interfasciculares e satélites perineuronais). No SNP, a glia é representada pelas células de Schwann. Em conjunto, essas células exercem diferentes funções na regulação e na manutenção do microambiente neural (MARTINS, 20, p. 20).

O Tecido Nervoso, de acordo com Montanari (2016), se encontra distribuído pelo organismo, contudo de forma interligada, resultando assim no sistema nervoso. De acordo com a autora o tecido apresenta uma considerável abundância e diversidade de células, sendo porém carente em matriz e elementos extracelulares.

\subsection{Astrócitos}

Os astrócitos são as maiores células da Glia do Sistema Nervoso Central, sendo também as que ocorrem em maior quantidade, excedendo o número de neurônios em proporção (Ramos et al., 2011). Ela apresenta uma morfologia estrelada, fator que dá origem ao seu nome, e em seu centro se encontra um núcleo grande de forma ligeiramente oval e irregular, com uma cromatina frouxa e nucléolo central. O citoplasma contém uma proteína ácida 
fibrilar, que atua como um filamento intermediário exclusivo dessas células no SNC. (Geneser, 2003 apud Montanari, 2016).

Eles são classificados de acordo com a quantidade e comprimento dos prolongamentos, divididos em protoplasmáticos ou fibrosos. Os protoplasmáticos tem em sua composição muitos prolongamentos, mas pequenos e espessos, enquanto o segundo apresentam menos prolongamentos, mas estes são longos e ricos em feixes de GFAP3.

Desde o século XIX, os astrócitos foram divididos em dois subtipos principais, protoplasmático e fibroso, com base em diferenças na morfologia celular e na localização anatômica. Os astrócitos protoplasmáticos são encontrados em toda a substância cinzenta e, como primeiro demonstrado por meio de técnicas clássicas de impregnação de prata, exibem uma morfologia de múltiplas ramificações, originando muitos processos curtos e finamente ramificados. São grandes, pouco corados e têm núcleo ovóide. Os astrócitos fibrosos são encontrados em toda a substância branca e exibem a morfologia de muitos processos longos, finos e pouco ramificados, com pouco citoplasma (MARTINS, 20, p. 24).

Dessa forma, trata-se de um único tipo de célula, com variações morfológicas determinadas pela localização, onde os astrócitos protoplasmáticos se encontram na substância cinzenta, ao passo em que os astrócitos fibrosos são encontrados na substância branca. Eles envolvem todo o sistema nervoso central, sem se sobreporem, mas de forma contínua, em um arranjo ordenado e organizado. Assim, os astrócitos fornecem um suporte metabólico e físico para os neurônios do SNC.

\subsection{Neurônios}

Os neurônios tem um corpo celular que possui um núcleo e outros elementos dos quais se originam os prolongamentos, na forma dos dentritos e axônios. Sua forma celular varia de acordo com o posicionamento, localização e 
atividade funcional do neurônio, que pode se apresentar como estrelado, piramidal, fusiforme ou esférica. (Junqueira; Carneiro)

No SNC, há uma segregação entre os corpos celulares dos neurônios e os seus prolongamentos, de modo que duas porções distintas sejam reconhecidas macroscopicamente: a substância cinzenta, onde se situam os corpos celulares dos neurônios e parte dos seus prolongamentos e as células da glia, e a substância branca, que contém somente os prolongamentos dos neurônios e as células da glia. A presença da mielina, um material lipídico esbranquiçado que envolve o axônio, é responsável pela coloração branca. (MONTANARI, 2016, p. 89).

Dependendo do número de prolongamentos, os neurônios podem ser classificados em neurônios bipolares, pseudounipolares e multipolares. Bipolares apresentam dois prolongamentos, um dendrito e um axônio. Pseudounipolares surgem como neurônios bipolares, mas ao longo do desenvolvimento fundem os dois prolongamentos próximo ao corpo celular. $\mathrm{E}$ multipolares apresentam mais de dois prolongamentos celulares, sendo a maioria dos neurônios. Quanto à função, podem ser sensoriais ou aferentes, que recebem estímulos sensoriais do meio ambiente e do próprio organismo, conduzindo as informações ao SNC, interneurônios, que se localizam no SNC e estabelecem ligações entre neurônios, e por fim neurônios motores ou eferentes, que surgem no SNC e conduzem os impulsos para os neurônios. (Montanari, 2016).

\subsection{Oligodendrócitos}

Localizados na substância cinzenta e na substância branca do Sistema Nervoso Central, os oligodendrócitos atuam como as células mielinizantes do SNC, produzindo os importantes internódulos das bainhas de mielina. São menores do que os astrócitos, possuindo poucos prolongamentos.

Na substância cinzenta eles se aproximam dos corpos celulares dos neurônios, havendo uma interdependência no metabolismo dessas células, no momento em que um determinado estímulo provoca transformações químicas 
no neurônio, que também vão ocorrer no oligodendrócito. E na substância branca, por meio de seus prolongamentos, envolvem segmentos de inúmeros axônios, onde o citoplasma é empurrado para o corpo da célula, restando praticamente apenas a membrana plasmática em torno do axônio. Nesse processo a camada envoltória é a bainha de mielina. (Montanari, 2016).

De acordo com Martins (2013), os oligodendrócitos estão constantemente e extensivamente em migração pelo SNC, até o momento de sua diferenciação final. É necessário que essa expansão ocorra de maneira similar à extensão dos corpos celulares neuronais, e determinadas moléculas da matriz extracelular.

Após a sua migração, as OPCs se estabelecem junto aos tratos de fibras da futura substância branca e depois se transformam em pré-oligodendrócitos, células que mantêm a propriedade de divisão celular e adquirem o marcador $\mathrm{O} 4$ (anticorpo monoclonal da superfície celular). Nesta fase, são menos móveis e perdem a sua resposta mitogênica ao fator de crescimento derivado de plaquetas (MARTINS, 20, p. 22).

O oligodendrócito, apesar de ser uma célula construtora da mielina, existem oligodendrócitos satélites que podem não se conectar de forma direta com a bainha da mielina. Ele se diferencia dos astrócitos, principalmente, por ser menor, possuir uma maior densidade nuclear e citoplasmática e por não possuir filamentos intermediários e a presença elementos fibrosos.

\section{MIELINA: ORIGEM, COMPOSIÇÃO E FUNÇÃO}

A bainha de Mielina é uma estrutura única, membranosa em espiral, composta por uma membrana lipídica rica em glicerofosfolipídeos e colesterol, recobrindo os axônios para facilitar a rápida comunicação entre os neurônios. É constituída da extensão da membrana plasmática das células Gliais mielinizantes, isto é, os oligodendrócitos no SNC e as células de Schwann (CS) no SPN. 
Nessa estrutura as células enviam essas extensões, dando origem a um segmento de invólucro no entorno de uma porção axonal, que é a bainha de mielina. De acordo com Martins (20, p. 28, várias particularidades estruturais caracterizam a mielina.

\begin{abstract}
A linha densa principal (LDP) é formada pelas superfícies citoplasmáticas das membranas dos processos mielinizantes colocadas em justaposição. Os dois folhetos exteriores fundidos (aposição extracelular) formam as linhas intraperiódicas (LIP), menos eletrodensas (GRAÇA, 1988; BONDAN; LALLO, 1998). A periodicidade das lamelas, ou seja, a distância entre os centros das LDP, é diferente na mielina central e periférica, sendo de 10,7 (5) nm para a primeira e de 11,9 (7) nm para a segunda, variação que possibilita a distinção das bainhas no SNC e do SNP em cortes transversais. Outro aspecto de importância para a mielina periférica é a presença de uma lâmina basal que envolve completamente a superfície de cada CS, além da existência de considerável quantidade de citoplasma na região adaxonal (BONDAN; LALLO, 1998). A bainha de mielina em torno da maioria dos axônios constitui a estrutura membranosa mais abundante no sistema nervoso dos vertebrados. Sua composição única, rica em lipídios e com baixo teor de água, permite o isolamento elétrico de axônios e sua singular estrutura segmentar, responsável pela condução dos impulsos nervosos saltatórios, permite que a bainha de mielina apoie a condução rápida nas fibras finas no sistema nervoso de vertebrados. Alta velocidade de condução, fidelidade de transferência de sinalização em longas distâncias e economia de espaço são as três principais vantagens conferidas ao sistema nervoso dos vertebrados pela bainha de mielina (SCHETTINGER; MORSCH, 2011). A importância da mielina no desenvolvimento humano é destacada por seu envolvimento em uma série de diferentes doenças neurológicas como leucodistrofias e esclerose múltipla (EM) no SNC e neuropatias periféricas no SNP.
\end{abstract}

Nessa dinâmica cada segmento é classificado como internodo, onde cada um destes internodos é interrompido em intervalos regulares, como explicitado anteriormente, o que forma os nodos de Ranvier. Estes, atuam como replicadores, e o impulso é fortalecido, estruturado e enviado de nódulo em nódulo. A mielina influencia na velocidade da condução, por meio da regulação do diâmetro do axônio, espessura da bainha de mielina, estrutura nodal e o número e o espaço de nódulos de Ranvier (Mendes e Melo, 2011). 
A correta coordenação da mielina necessita de uma comunicação recíproca entre neurônios e oligodendrócitos, onde cada parte da bainha é formada através de moléculas estruturadas e organizadas que a sintetiza. Ao longo de seu processo de formação as células oligodendrócitos promovem a extensão de processos e segmentos celulares que alcançam os axônios, posicionando-se em torno deles, variando de 10 a 30 segmentos axonais em cada mielinização. (Mendes e Melo, 2011).

Essa dinâmica ocorre no SNC a partir das células precursoras de oligodendrócitos, que se proliferam e migram para o desenvolvimento da substância branca. Com isso ocorre o reconhecimento dos axônios alvos, onde em seguida irá ocorrer a diferenciação de oligodendrócitos e oligodendrócitos mielinizantes, promovendo o crescimento da membrana e seu envolvimento em axônio. Assim a mielina é compactada para ocorrer a formação dos nodos, necessária para a comunicação. (Simon; Klaus; Nave, 2016).

No que tange à composição molecular da bainha da mielina, pode-se afirmar que sua estrutura é carente de hidratação, devido à sua riqueza em lipídeos, não contendo nem mesmo $50 \%$ de água, comparados aos $80 \%$ dos neurônios. (Simon. Klaus, Nave, 2016).

\subsection{Mielinização, Desmielinização e Remielinização}

A bainha da mielina, como explicitado anteriormente, permite a transmissão saltatória, de maneira rápida e eficaz no Sistema Nervoso. A partir das células que constroem a mielina é possível compreender sua importância para todo o Tecido Nervoso. Nesse contexto o processo de mielinização envolve interações estreitas e complexas entre os axônios e suas células bainha, onde a interação se inicia a partir de um sinal emitido pelo axônio, que recruta populações celulares com potencial mielinizantes, "na sua diferenciação e proliferação e na iniciação da síntese e manutenção das moléculas específicas da mielina." (GRAÇA, 1988, p. 283). Além disso há a presença de um terceiro 
fator para promover a estabilidade das relações entre ambos, que no SNC é constituído por fibras colágenas preformadas.

Formação da bainha de mielina - O processo de mielinização se inicia quando uma projeção da célula-bainha envolve o axônio e forma espiral frouxa ao seu redor. Com o tempo as camadas formadas se compactam pela expulsão do citoplasma e formam estrutura lamelar com bandas eletrodensas espessas derivadas da aposição das fases citoplasmáticas das membranas - e menos eletrodensas - derivadas da aposição das fases externas das membranas. Ambas as bandas recebem a denominação de linha densa principal (LDP) e linha intraperiódica (LI) respectivamente. (GRAÇA, 1988, p. 293).

No processo de desmielinização ocorre o dano segmentar à mielina, sem lesão axonal, distinguindo assim da chamada degeneração walleriana, onde ocorre a degradação da mielina a partir da degeneração axonal. Esse processo é frequente em diversas doenças espontâneas, tal como a esclerose múltipla no ser humano e a cinomose nos cães, por exemplo.

\begin{abstract}
Após a exposição da substância branca a agentes lesivos, a mielina sofre degradação associada a infiltração macrofágica na área. As bainhas podem sofrer alterações antes de ser fagocitadas, tais como vesiculação e formação de fava, micropinocitose vermiforme e desnudamento, associado a profusa infiltração macrofágica. Os axônios desmielinizados podem ser remielinizados ou permanecer desprovidos de suas bainhas, separados por processos de astrócitos. Nos casos em que os astrócitos estão ausentes da área da lesão, os axônios se aglutinam. (GRAÇA, 1988, p. 295)
\end{abstract}

Por fim o termo remielinização se refere à reconstrução de bainhas de mielina perdida. No caso da esclerose múltipla, há uma falha na remielinização, e isso contribuiu para que se pensasse que esse processo não se inserir no SNC, e embora seja cientificamente possível, depende de diversos fatores, podendo ser efetivada pelo oligodendrócito ou pela célula de Schwann.

Os internódulos reconstruídos no SNC são reconhecidos principalmente pela espessura da bainha de mielina, que é mais fina que o normal para o diâmetro do axônio. A distinção entre um internódulo reconstruído por um oligodendrócito ou por uma célula de Schwann se faz pela periodicidade das lamelas de mielina - que é maior no SNP — e pela presença de membrana 
basal ao redor da célula de Schwann. Quando o processo de remielinização é feito pelas duas células-bainha, os oligodendrócitos se localizam adjacentes à substância branca normal enquanto as células de Schwann se distribuem nas áreas perivasculares e subpiais. (GRAÇA, 1988, p. 295)

Concluindo, atualmente é conhecido que a substância branca do SNC possui uma grande capacidade de reparação, a partir de oligodendrócitos ou pelas células de Schwann, que invadem o SNC toda vez que os astrócitos são degenerados.

\section{CONCLUSÃO}

Analisar a bainha de mielina contribui para o levantamento de significativas informações acerca de sua formação, composição e função desse mecanismo neuronal, fundamental para o Tecido Nervoso. A substância branca, que até pouco tempo dentro da literatura era classificada como coadjuvante na dinâmica neuronal, comprova seu papel de destaque para o funcionamento nervoso. Nesse contexto as células oligodendrócitos e a mielina possuem papel indispensável para o funcionamento cerebral e saúde mental.

ABSTRACT: Formed by bimolecular layers of lipids interspersed with proteins, myelin constitutes an important element of the Central and Peripheral Nervous System, acting as a sheath that surrounds the nervous tracts, facilitating rapid communication between neurons. They are synthesized and maintained by oligodendrocytes, one of the most vulnerable cells in the nervous system, which form a variable number of myelin segments, called internodules, that vary between 1 and 200. In this way, when damage to a cell occurs, countless can be destroyed internodules, in a process called demyelinating, causing a series of complications. Thus, this work aims to analyze the function of myelin in the nervous system and the clinical complications of its degeneration.

KEYWORDS: Myelin. Central Nervous System. Degeneration. 


\section{Nota(s) explicativa(s) da página 2}

Região não mielinizada, localizada entre uma célula de Shwann e outra, formada a partir da descontinuidade da mielina que se interrompe em intervalos regulares, onde ocorre pequenos segmentos de 1 a $2 \mathrm{~mm}$, e entre eles há uma área isenta de axônio. Como a mielina atua como um isolante, as alterações de polaridade da membrana ocorrem apenas nos nódulos de Ranvier, com o impulso saltando de um nódulo para outro. (Montanari, 2016).

São locais em que ocorrem o contato entre dois neurônios, ou entre um neurônio e uma célula efetora. (Montanari, 2016).

Filamento intermediário exclusivo dos astrócitos, responsável por sua comunicação. (Geneser, 2003). 


\section{REFERÊNCIAS}

LIMA, Rafael Rodrigues et al. Lesão da substância branca e doenças neurodegenerativas. Rev. Para. Med., Belém, v. 20, n. 4, p. 41-45, dez. 2006.

Disponível em <http://scielo.iec.gov.br/scielo.php?script=sci_arttext\&pid=S0101$59072006000400008 \&$ Ing=pt\&nrm=iso>. Acessos em 05 nov. 2020.

GENESER, F. Histologia: com bases moleculares. 3.ed. Buenos Aires: Médica Panamericana/ Rio de Janeiro: Guanabara Koogan, 2003.

GRAÇA, Dominguita Lühres. Mielinização, Desmielinização e Remielinização no Sistema Nervoso Central. Arq. Neuro-Psiquiatra, São Paulo, v. 43, 1988.

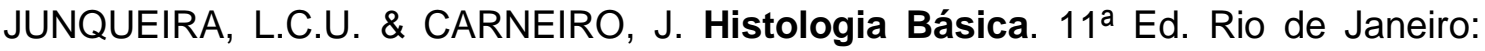
Guanabara Koogan, 2008.

MARTINS, Maria de Fátima Monteiro. Estudo morfológico do processo remielinizante no tronco encefálico de ratos diabéticos tratados com ciclosporina. Tese de doutorado apresentada ao Programa de Pós Graduação em Patologia Ambiental e Experimental da Universidade Paulista, São Paulo, 2013.

MENDES, Priscilla Balestrin, MELO, Silvana Regina. Origem e desenvolvimento da mielina no Sistema Nervoso Central - um estudo de revisão. Revista Saúde e Pesquisa, v. 4, n. 1, p. 93-99, jan./abr. 2011.

MONTANARI, Tatiana. Histologia: texto, atlas e roteiro de aulas práticas - 3. ed. Porto Alegre: Edição do Autor, 2016.

SILVA, MARCUS TULIUS TEIXEIRA DA; CAVALCANTI, JOSÉ LUIS DE SÁ; MOREIRA, DENISE MADEIRA. Alterações neurorradiológicas cerebrais na degeneração combinada de medula: relato de caso. Arq. Neuro-Psiquiatr., São Paulo, v. 58, n. 3A, p. 752-755, Sept. 2000 Available from <http://www.scielo.br/scielo.php?script=sci_arttext\&pid=S0004-

282X2000000400026\&lng=en\&nrm=iso>. access on 07 Nov. 2020. 